\title{
"A condição para quem nasce negra e mulher é ser doméstica?": desigualdade entre mulheres brancas e negras no trabalho doméstico
}

\begin{abstract}
Resumo
O presente estudo pretende fazer algumas considerações sobre o trabalho doméstico e as desigualdades presentes nesta atividade, que atingem igualmente mulheres brancas e negras. Concatenam-se, para isto, um estudo exploratório com investimento bibliográfico e um estudo feito pelo IPEA sobre a situação atual das trabalhadoras domésticas no País ao longo da última década (1999-2009), com base em dados da Pnad/IBGE. O trabalho doméstico é subvalorizado, marcado pela invisibilidade, por situações de vulnerabilidade e informalidade. É inegável que, ao longo do tempo, esta atividade trouxe as velhas expressões de desigualdade experimentadas há anos por distinção de raça/cor. Conclui-se constituir uma atividade que há muito absorve a mão de obra feminina, majoritariamente de negras. Observou-se um aumento da ocupação em função da autodeclaração. Tem maior proporção junto às negras, condicionando sua participação e entrada no mercado de trabalho. Houve um aumento da escolaridade das trabalhadoras domésticas negras, mas ainda não conseguiram se equiparar às brancas, até por conta dessa inferioridade escolar. Percebeu-se um aumento da formalização quando se compara a proteção social via contribuição para a previdência. Na relação trabalhoprevidência, condição para reconhecimento da profissão e até mesmo da valorização, as negras estão atrás das brancas.
\end{abstract}

Guélmer Júnior Almeida de Faria

Mestre em Desenvolvimento Social pela Universidade Estadual de Monte: Claros - Brasil. guelmerjrf@yahoo.com.br

Maria da Luz Alves Ferreira Doutora em Sociologia e Política pela Universidade Federal de Minas Gerais Professora da Universidade Estadual d Montes Claros - Brasil. mariadaluz@oi.com.br

\section{Caroline Marci Fagundes Coutinho} Mestra em Desenvolvimento Social pela Universidade Estadual de Monte:

Claros - Brasil karol_marci@hotmail.com

Palavras-chave: Estratificação social; raça/cor; Trabalho doméstico.

\section{Para citar este artigo:}

FARIA, Guélmer Júnior Almeida de; FERREIRA, Maria da Luz Alves; COUTINHO, Caroline Marci Fagundes. "A condição para quem nasce negra e mulher é ser doméstica?": desigualdade entre mulheres brancas e negras no trabalho doméstico. Revista PerCursos. Florianópolis, v. 15, n.28, p. 354 - 375. jan./jun. 2014. 


\title{
"Is the condition of those who are born black and female is to be domestic worker?": inequality between white women and black women in domestic labor
}

\begin{abstract}
This paper aims to present some considerations about the domestic labor and inequalities present in this activity when compared with white and black women. For this, concatenate an exploratory study of bibliographic investment and a study by IPEA on the current situation of domestic workers in the country over the last decade (1999-2009) based on survey data from PNAD/IBGE. Therefore, to address the issue of inequality between black and white women in relation to domestic work. Domestic work is undervalued, marked by invisibility, for vulnerability and informality. It is undeniable that over time this activity has brought old expressions of inequality experienced for years by distinction of race / color. It is concluded that domestic work is an activity that absorbs long labor, female labor is mostly composed of black. There was an increase in occupancy due to the self-declaration. Have a greater proportion of black women, conditioned on participation and input of black women in the labor market. There was an increase in the education of black domestic workers, but compared to white women have yet to match, and has its insertion in the labor market with lower education. Noticed an increased formalization and when comparing social protection via the pension contribution, are behind the black white, a condition for recognition of the profession and even appreciation
\end{abstract}

Keywords: social stratification; race/color; domestic labor. 


\section{Introdução}

O tema da desigualdade é recorrente nos debates sobre a estrutura e formação das classes sociais entre sociólogos. A análise das estruturas de classe e de suas estratificações é uma ferramenta metodológica desenvolvida pelos cientistas sociais dos países ocidentais para estudar os sistemas básicos de estratificação nas sociedades humanas.

Na visão de Melvin Tumin:

Embora o uso corrente quase sempre empregue estratificação social e não desigualdade social, sob o ponto de vista prático, os termos são sinônimos. A estratificação tem sido definida como a disposição de qualquer grupo ou sociedade numa hierarquia de posições desiguais com relação de poder, propriedade, valorização social e satisfação psicológica (TUMIN, 1970, p. 27).

Esta interpretação da sociedade é um dos fatores importantes para estudar a redução das desigualdades geradas pelo grau de desenvolvimento econômico de um país. No Brasil, o tema é complexo, pois envolve, além dos critérios individuais, os atributos estruturais advindos de uma sociedade assentada em características patriarcais e escravocratas. A dívida social para com o segmento negro até os dias atuais é de difícil transposição.

Segundo Souza (2011), a desigualdade racial no mercado de trabalho brasileiro é uma realidade que ainda impõe à população negra uma série de restrições que dificultam sua ascensão social. Apesar da distância no tempo do período da escravatura, a estrutura social no País ainda reflete profundas desigualdades raciais, mostrando que negros e pardos, se comparados com outros grupos, continuam em posições inferiores.

Seguindo esta visão, as desigualdades sociais seriam apenas fundadas na questão de classe e não na desigualdade de raça/cor. Negros e brancos, portanto, se equiparariam diante das barreiras para alcançar ascensão social e o desenvolvimento socioeconômico, que proporcionaria maior mobilidade social. 
No entanto, barreiras de várias naturezas podem comprometer a igualdade de acesso a determinados grupos, com relação a oportunidades de compartilhamento dos resultados referentes ao crescimento econômico e social de uma nação.

Para Frankin Parkin:

se a estratificação é marcada, no seu início, pela relutância em tratar a etnicidade como pouco mais do que uma leve perturbação na superfície da estrutura de classes, há agora indicações de uma completa inversão teórica, é hoje a classe que pode ser tratada como característica agravante do sistema social, modelado em grande parte pelas realidades das forças étnicas (PARKIN, 1980, p. 812-13).

Vários autores abordaram as relações raciais e perceberam que a ascensão social depende de fatores universais como: origem familiar, investimento em capital humano e capacidade de aproveitamento das oportunidades de vida, com destaque para os trabalhos de Gilberto Freire, Florestan Fernandes e Donald Pierson. Há também outro segmento de autores - como Carlos Hasenbalg, Antônio Sérgio Guimarães e Nelson do Valle Silva -, com outra interpretação das relações de raça/cor no Brasil.

Para esses autores, apesar dos fatores universais, no caso de negros, pardos e mulatos, as barreiras raciais se sobrepõem a tais fatores e representam o maior obstáculo para sua mobilidade e ascensão social.

O tema da desigualdade entre mulheres negras e brancas em relação ao trabalho doméstico deve ser tratado de acordo com o que preconizam Bernardino-Costa, Figueiredo e Cruz (2011). A análise sobre trabalho doméstico, tema tão caro a mulheres meninas, adolescentes e adultas -, merece uma reflexão sobre suas implicações em sua vida. Consideramos primordial levantar questionamentos que nos permitam compreender a difícil tarefa da conquista de direitos para as mulheres, negras, pobres e que exercem atividades profissionais no mundo doméstico, espaço este já levantado por vários teóricos como lugar de não prestígio, de não cidadania, de não direito, de não pessoa. 
Transformar a situação atual das trabalhadoras domésticas em todo o mundo, de acordo com Sanches (2009, p. 879), significa ultrapassar incontáveis preconceitos, estereótipos e discriminações que pesam sobre essa atividade, fruto de heranças históricas do patriarcalismo, da servidão e da escravatura e que se reconstruíram, de outras formas, nas sociedades capitalistas modernas:

\begin{abstract}
Assim, se é verdade que a igualdade formal é garantida em nosso país e que a presença de preconceitos e discriminações não é aceita no corpo jurídico vigente, por outro lado a igualdade real não se concretiza, o que pode ser visualizado pelos indicadores apresentados, que explicitam claramente as enormes desigualdades que sofrem as mulheres e os negros, e, em consequência da interseccionalidade, as mulheres negras. Esta violação aos direitos humanos torna-se ainda mais grave quando constatamos a magnitude da população brasileira que está sujeita, cotidianamente, a agressões, humilhações e outros tipos de violências não expressas ou simbólicas não baseadas em seu sexo ou em sua cor ou raça (PINHEIRO et al., 2006, p. 4).
\end{abstract}

Neste artigo, as considerações sobre a desigualdade na atividade doméstica entre mulheres brancas e negras terá por referência um estudo exploratório com investimento bibliográfico e um estudo feito pelo Instituto de pesquisa econômica aplicada (IPEA) sobre a situação atual das trabalhadoras domésticas no país ao longo da última década (1999-2009), com base em dados da Pesquisa Nacional por Amostra de Domicílios (Pnad), do Instituto Brasileiro de Geografia e Estatística (IBGE).

\title{
Revisão de Literatura
}

\section{Relação de Raça/Cor e Trabalho Doméstico}

A expansão da classe média pelo processo de urbanização e industrialização transformou a relação trabalho doméstico-serviçal em serviço doméstico. Brites (2000) evidencia que o processo de urbanização e modernização da nossa sociedade brasileira promoveu o deslocamento das relações de poder, apesar do distanciamento cada vez mais acentuado entre dominantes e subalternos. A empregada doméstica constituiu-se em personagem importante, capaz de ligar mundos bastante díspares. 
No Brasil, em 2007, o trabalho doméstico remunerado empregava 6.731.197 pessoas, das quais 94\% eram mulheres, segundo dados da Pnad/IBGE, apresentados no Retrato das Desigualdades. Destas mulheres, 61\% eram negras e 39\%, brancas. É a principal ocupação feminina, respondendo por $16,4 \%$ do trabalho das mulheres, e é especialmente importante para as mulheres negras: $21,4 \%$ delas trabalham como domésticas, em comparação a 12,1\% entre as mulheres brancas (SANCHES, 2009, p. 882).

Historicamente, o trabalho doméstico sempre carregou o estigma da servidão, com a cooptação de "moças do interior" para "ajudar" a servir a nova classe burguesa que estava emergindo, primeiro, e com a omissão do poder público sobre a esfera privada, depois, fato que ajudou a manter essa relação de trabalho na invisibilidade.

No Brasil, o trabalho doméstico é realizado principalmente por mulheres, negras em sua maioria. Em 2008, 6,2 milhões de mulheres eram trabalhadoras domésticas, representando $15,8 \%$ do total da ocupação feminina e $20,1 \%$ do total da ocupação de mulheres negras. Menos de 30\% do total das trabalhadoras domésticas tinham carteira de trabalho assinada e acesso à previdência social (INSTITUTO DE PESQUISA ECONÔMICA APLICADA, 2010).

Hooks (1995) considera que o sexismo e o racismo, atuando juntos, perpetuam uma iconografia de representação da negra que imprime na consciência cultural coletiva a ideia de que ela está neste planeta principalmente para servir aos outros.

A composição cor/raça era, em 2004, de 51,4\% de brancos; 42,1\% de pardos; 5,9\% de pretos; $0,4 \%$ de amarelos e $0,2 \%$ de indígenas. Isto significa que quase metade da população brasileira é potencialmente vítima das discriminações raciais e sofre com as desigualdades não educacionais no mercado de trabalho, no acesso a bens e serviços. Seguindo a mesma lógica, mais da metade da população está sujeita a diversas formas de discriminação em função do sexo: em 2004, o Brasil era composto por 48,7\% de homens e 51,3\% de mulheres (PINHEIRO et al., 2006, p. 5).

Com base em Hirata (2004), a servidão significa estar sempre à disposição do outro ou da outra; implica fazer uma atividade qualquer do jeito que o outro ou a outra 
gosta; significa ser considerada naturalmente uma espécie de adivinhadora dos desejos dos(as) outros(as), com total disponibilidade de tempo.

Freitas (2009) aponta as representações dessa hierarquização no plano microssociológico. Segundo sua análise, a hierarquização se faz em base à raça, que se torna um diferencial nas interações no ambiente do trabalho doméstico. Por conta disso, grupos com identidades sociais diferentes são colocados em situação de confronto. Afinal, o conceito de raça é uma construção social que envolve hierarquizações diversas relações de poder -, e é usado para estabelecer ou manter estigmas.

Segundo Souza (2011), as desigualdades raciais persistem na sociedade brasileira e influenciam negativamente as condições de vida da população negra. No mercado de trabalho brasileiro, as pesquisas oficiais conduzidas pelo IBGE, pelo IPEA ou por organizações não governamentais de cunho racial retratam as diferenças de inserção, de ocupação e de remuneração entre brancos e negros.

Assim, de acordo com a Organização Internacional do Trabalho (OIT, 2010), o trabalho doméstico é uma significativa fonte de ocupação para muitas mulheres no mundo e porta de entrada no mercado de trabalho para as mais pobres e negras.

Os/as trabalhadores/as domésticos/as são uma parcela expressiva da força de trabalho no mundo. Segundo a OIT, estimativas conservadoras apontam mais de 100 milhões de pessoas que representam de $4 \%$ a10\% da ocupação total (feminina e masculina) nos países em desenvolvimento e cerca de $1 \%$ a 2,5\% nos países desenvolvidos. Na América Latina, o trabalho doméstico conta com aproximadamente 12 milhões de pessoas e representa 14\% da ocupação feminina na região (SANCHES, 2009, p. 880).

Em Bento (1995) encontramos o seguinte esclarecimento: o lugar da mulher negra no trabalho está demarcado no gueto da subalternização e da realização de atividades manuais, ou serviços domésticos, tais como os de babá, servente, cozinheira e lavadeira/passadeira.

Neste sentido, é válido ressaltar o argumento de Cruz (2011), segundo o qual essa atividade se desenvolve sob estereótipos e construções de gênero e raça intrinsecamente ligados à naturalização de elementos inferiorizadores da mulher negra. Historicamente, o 
trabalho exercido por mulheres é socialmente desvalorizado, sob o argumento sexista que o considera como de segunda ordem - vide as díspares remunerações entre os gêneros. Quando essa lógica alcança as trabalhadoras negras, soma-se a discriminação racial, que as inferioriza, explora e subalterniza.

De acordo com o Departamento Intersindical de Estatística e Estudos Socioeconômicos (Dieese), os maiores percentuais de vulnerabilidade da mulher negra no universo dos trabalhadores ocupados se explicam, sobretudo, pela intensidade de sua presença no emprego doméstico. Esta atividade, tipicamente feminina, é desvalorizada aos olhos de grande parte da sociedade, caracterizando-se pelos baixos salários e elevadas jornadas, além de altos índices de contratação à margem da legalidade e ausência de contribuição à previdência (DEPARTAMENTO INTERSINDICAL DE ESTATÍSTICA E ESTUDOS SOCIOECONÔMICOS , 2005).

Na visão de Montagner (2004), cabe, nas diferenciações sexuais no mundo do trabalho, um registro importante sobre questões relativas a etnia e raça, porque a situação de mulheres brancas e mulheres negras não é a mesma. Negros e pardos recorrentemente ocupam postos de trabalho com menor qualificação e maior volatilização social: têm maior taxa de desemprego, maior dificuldade de reinserção e menores salários. Historicamente, a mulher branca conseguiu alguma melhora no mundo do trabalho; porém, isto não aconteceu com relação à mulher negra.

Segundo Pinheiro et al. (2006), as mulheres negras são mais de 43 milhões de pessoas, o que representa $24,1 \%$ do total da população brasileira. São elas que sofrem com o fenômeno da dupla discriminação, ou seja, estão sujeitas a múltiplas formas de discriminação social, em consequência da conjugação perversa de racismo e sexismo, que resultam em uma espécie de asfixia social, com desdobramentos negativos sobre todas as dimensões da vida.

Para Hasenbalg (1979), a população negra no mercado de trabalho no Brasil também está sujeita aos mecanismos de dominação de classe que afetam outros grupos. No entanto, os negros sofrem, ainda hoje, uma discriminação peculiar em função da sua condição racial. 
No dizer de Souza (2011), no mercado de trabalho, as mulheres negras vivenciam uma dupla discriminação - de gênero e raça. Articulados e silenciados, o preconceito e a discriminação contra as trabalhadoras negras reforçam essa demarcação de espaços, dificultando ainda o desenvolvimento profissional e pessoal deste grupo. Em contextos de crises do mercado de trabalho, esse é o grupo mais vulnerável, com maiores dificuldades de acesso aos processos de desenvolvimento profissional.

\section{Análise do perfil de mulheres brancas e negras no trabalho doméstico}

$\mathrm{Na}$ década analisada pelo IPEA sobre a situação atual das trabalhadoras domésticas no país ao longo da última década (1999-2009), com base em dados da Pnad/IBGE, o trabalho doméstico remunerado comportava, em 2009, cerca de 7,2 milhões de trabalhadores e trabalhadoras, ou 7,8\% do total de ocupados no País. Esta atividade, porém, não tem a mesma importância para homens e mulheres, ou para negros e brancos. De fato, o trabalho doméstico é - e sempre foi - uma ocupação desempenhada majoritariamente por mulheres e negras (INSTITUTO DE PESQUISA ECONÔMICA APLICADA, 2011).

Quanto ao perfil das trabalhadoras domésticas negras para o mesmo período, em 1999 representavam 55\%; em 2009, 61,6\% (Gráfico 1), ou seja, houve um aumento, explicado primeiramente pela autodeclaração. Tais percentuais confirmam a visão de Souza (2011), de que os primeiros trabalhos de investigação que procuraram analisar a inserção da mulher negra no mercado de trabalho, no Brasil, enfrentaram inúmeras dificuldades, principalmente no campo dos dados oficiais. Um exemplo é a não inclusão do quesito cor nos levantamentos oficiais de alguns anos, afora a inexistência de análises distintas para os dois grupos de mulheres. 
“A condição para quem nasce negra e mulher é ser doméstica?": desigualdade entre mulheres brancas e negras no trabalho doméstico

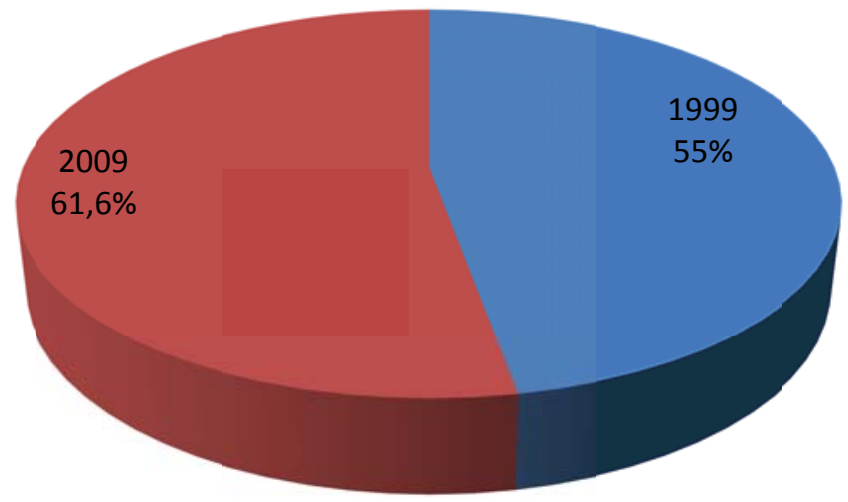

Fonte: Elaborado pelos autores, com base no Pnad/IBGE, 2009.

O perfil dessa ocupação tem, assim, ocupado posição central nas possibilidades de incorporação das mulheres ao mercado de trabalho, particularmente das negras, pobres e sem escolaridade ou qualificação profissional. Portanto, ainda assume características de socialização e oportunidade de primeiro emprego, por considerar as atividades domésticas como algo inato à condição da mulher. De acordo com Melo (1998), o serviço doméstico remunerado tem um papel importante na absorção das mulheres de menor escolaridade e sem experiência profissional no mercado de trabalho.

Em relação à importância do trabalho doméstico para as mulheres, quando se compara ao das mulheres brancas, percebe-se que, para as negras, representa $21,8 \% \mathrm{da}$ ocupação das mulheres deste grupo racial e, para as brancas, 12,6\% (Gráfico 2), configurando que a participação e a entrada das mulheres negras no mercado de trabalho estão condicionadas à sua inserção no trabalho doméstico. 


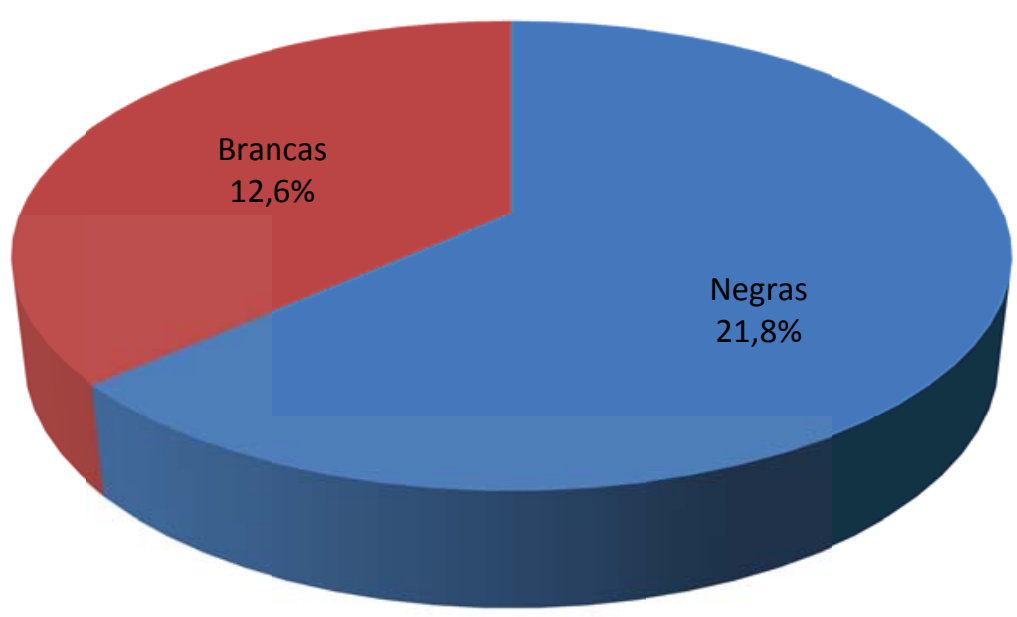

Fonte: Elaborado pelos autores, com base na Pnad/IBGE, 2009.

Este fenômeno, para o IPEA (2011), está relacionado a uma herança escravista da sociedade brasileira, que se combinou na construção de um cenário de desigualdade no qual as mulheres negras têm menor escolaridade e maior nível de pobreza e no qual o trabalho doméstico desqualificado, desregulado e de baixos salários constitui uma das poucas opções de emprego.

Quanto à escolaridade, observa-se que as trabalhadoras domésticas negras possuem escolaridade menor que a das brancas; em 1999 as brancas possiuíam cerca de 5 anos de estudo, em média, contra 4,4 anos das negras. Ao longo da déicada, em 2009, pode-se constatar um aumento nos anos de estudos deste segmento: para as trabalhadoras domésticas brancas, saltou para 6,4 anos; para as negras, para 6,0 (Gráfico 3). Esse aumento se explica pela universalização do ensino fundamental, através de programas educacionais, com foco na educação de jovens e adultos, albsorvendo com maior impacto uma parte da população que não tinha acesso à educação.

Silva e Lima (1992) realizaram um estudo sobre o tema com dados da Pnad de 1987. Uma das primeiras conclusões foi a constatação de que a escolaridade era um fator favorável à participação da mulher no mercado de trabalho. No entanto, as mulheres 
“A condição para quem nasce negra e mulher é ser doméstica?": desigualdade entre mulheres brancas e

negras, devido às suas condições socioeconômicas desfavoráveis, ingressavam nesse mercado com uma escolaridade inferior.

Gráfico 3 - Escolaridade segundo raça/cor

$$
\text { Brancas } \square \text { Negras }
$$

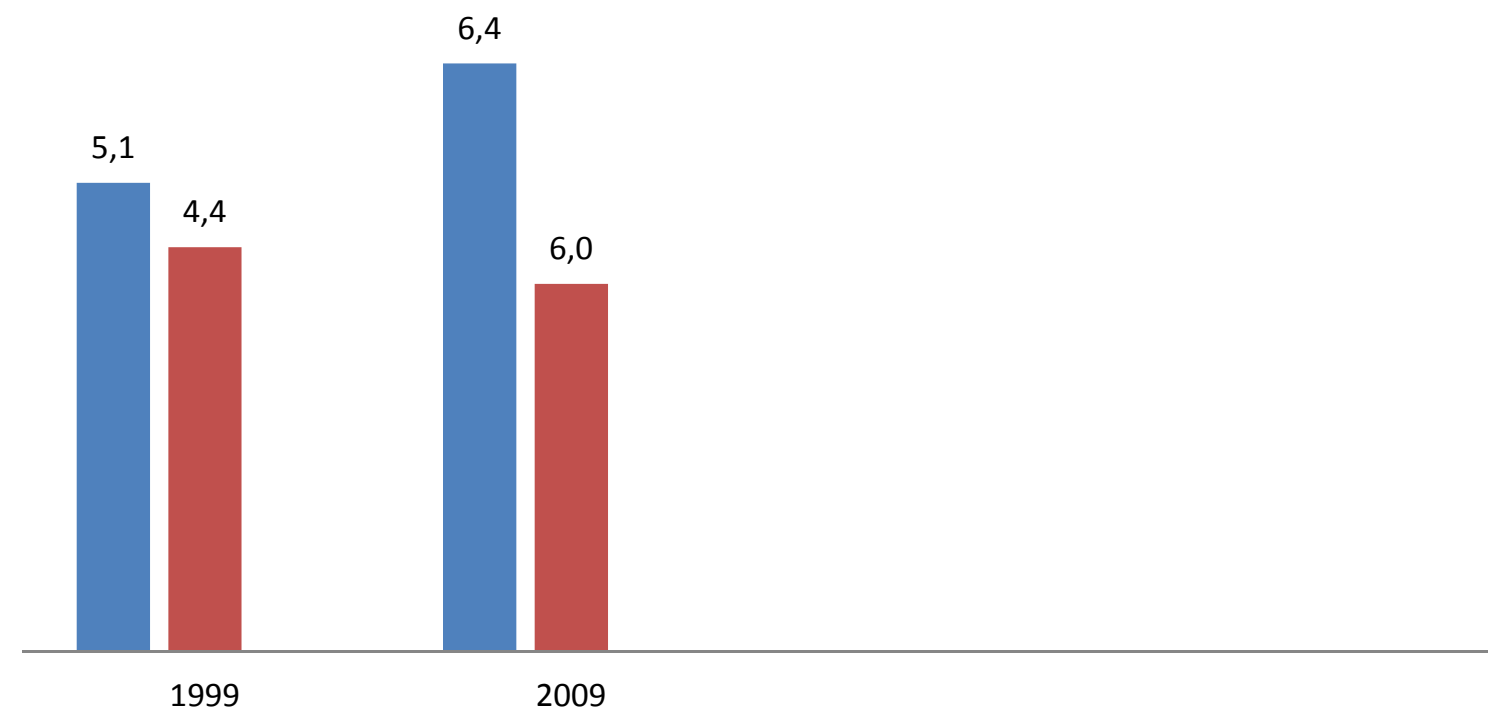

Fonte: Elaborado pelos autores com base na Pnad/IBGE, 2009.

Uma questão-chave para tornar o trabalho doméstico reconhecido é a formalização do contrato de trabalho que se dá pela carteira de trabalho assinada, uma das garantias de proteção social, condição para reconhecimento da profissão e até mesmo de valorização. Em 1999, as trabalhadoras domésticas negras representavam $21,2 \%$, enquanto que as brancas, $26,9 \%$. Ao longo da década, houve um aumento para as negras, chegando a 24,2\%, e a 29,3\% para as trabalhadoras domésticas brancas (Gráfico 4). 
GRÁFICO 4 - Trabalhadoras domésticas com carteiras assinada

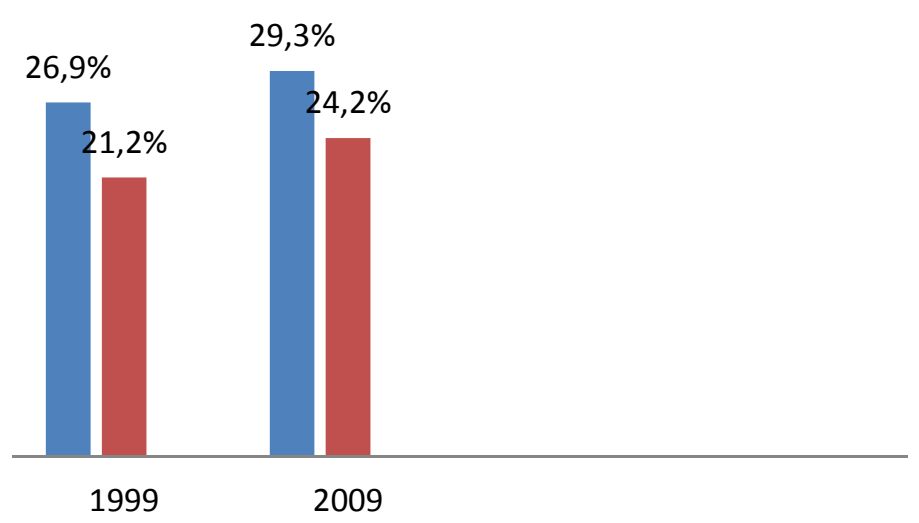

Fonte: Elaborado pelos autores com base na Pnad/IBGE, 2009.

Segundo Mattos (2009), o mercado de trabalho doméstico tem de ser considerado como de fato é, um ambiente relacional, em um país de desigualdade de renda e oportunidades, mas onde o pacto de mútuo benefício deve ser protegido e incentivado, favorecendo a livre empregabilidade, expurgando aqueles que confundem proximidade de relação de emprego dentro de casa com direito ilimitado ao trabalho do outro.

A PEC 66/2012, aprovada pela Câmara dos Deputados em abril de 2013, modifica o parágrafo único do artigo $7^{\circ}$ da Constituição, acrescentando novos direitos aos que já são garantidos aos empregados domésticos. No entanto, forças sindicais e outros setores da sociedade ainda se manifestam temerosos relativamente à nova legislação. A formalização poderá provocar uma queda nos contratos e estimular a informalidade.

Uma das alternativas para superar essa dívida social para com as trabalhadoras domésticas é a condição de contribuintes autônomas com a Previdência Social. Em 1999, as mulheres negras representavam $22,8 \%$ e as brancas, $29,6 \%$. Numa análise ao longo da década, observa-se que o cenário comporta, para as trabalhadoras domésticas negras, 
27,8\%, seguido de 33,9\% para as brancas (Gráfico 5). Percebe-se um aumento relativo, tanto no segmento da categoria negra, quanto no da branca.

GRÁFICO 5 - Proporção de trabalhadoras domésticas que contribuem para a Previdência Social, segundo raça/cor

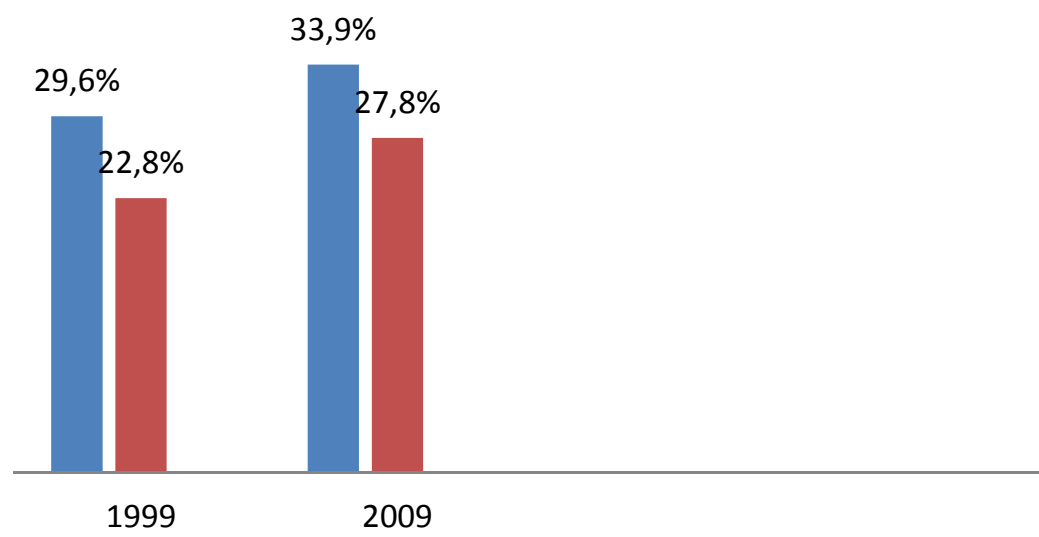

Fonte: Elaborado pelos autores com base na Pnad/IBGE, 2009.

Para o IPEA (INSTITUTO DE PESQUISA ECONÔMICA APLICADA, 2011), o reduzido número de trabalhadoras que conseguem contornar a desproteção social pela contribuição individual aponta para importantes gargalos que devem ser considerados pelos executores das políticas. Em primeiro lugar, há que se levar em conta que, diante dos baixos salários recebidos pelas trabalhadoras e das precárias condições de trabalho e de vida, o fato de terem de arcar sozinhas com a contribuição previdenciária (correspondente de $8 \%$ a $11 \%$ da renda) é um peso que grande parte destas mulheres não consegue sustentar.

Em relação à raça/cor declarada das trabalhadoras domésticas que residiam nos domicílios em que trabalhavam, na tabela 1 (em relação à idade) podem-se observar diferenças expressivas quando se analisa o perfil etário das residentes e das que não residem. Um maior número de mulheres jovens negras $(30,8 \%)$, dentre as trabalhadoras 
domésticas, tinha até 24 anos e residia no local de trabalho; uma proporção maior de mulheres idosas brancas (10,1\%) mora no domicílio. Destacam-se também as mulheres na faixa etária de 30 a 44 anos, que não moram no domicílio: entre as brancas, 42,8\%; entre as negras, 42,7\%. Na faixa etária de 45 a 59 anos, as que não moram no domicílio representam 29,6\% entre as brancas e, entre as negras, $24,9 \%$.

O envelhecimento da categoria, segundo Melo e Di Sabatto (2011), fica evidente em 2009, representando 18,8\%, ou aproximadamente 1,3 milhão das trabalhadoras. As domésticas, como os demais trabalhadores, estão maciçamente na faixa de 30 a 49 anos. É interessante chamar atenção para o fato de esta ser uma característica desta última década. Entre 2001 e 2009, houve um significativo aumento do contingente de trabalhadoras com idade entre 30 e 49 anos.

O que é importante notar é que, mesmo com uma mudança significativa no perfil etário das trabalhadoras domésticas, ainda persiste uma considerável diferença no perfil etário entre as residentes e não residentes, e entre brancas e negras.

Segundo Melo (1998), as trabalhadoras domésticas residentes têm uma relação de ambiguidade: o alojamento e a comida são vistos como uma regalia e ajuda dos patrões.

Outro entendimento é que esses dados parecem sinalizar para um fenômeno pouco estudado, que é o da migração de mulheres e sua inserção no trabalho doméstico. São as mulheres jovens e negras, de baixa renda, que migram para trabalhar e morar nas casas de família nas grandes cidades. Aqui se estreitam os laços da relação patroa $x$ empregada, gerando maior vulnerabilidade e desamparo.

Tabela 1 - Distribuição das trabalhadoras domésticas que moram e que não moram nos domicílios em que trabalham, segundo as faixas etárias e raça/cor

\begin{tabular}{c|cccccc}
\hline \multicolumn{2}{c}{ Brancas } & \multicolumn{2}{c}{ Negras } & \multicolumn{2}{c}{ Total } \\
\hline $\begin{array}{c}\text { Faixa } \\
\text { etária }\end{array}$ & $\begin{array}{c}\text { Mora no } \\
\text { domicílio }\end{array}$ & $\begin{array}{c}\text { Não mora no } \\
\text { domicílio }\end{array}$ & $\begin{array}{c}\text { Mora no } \\
\text { domicílio }\end{array}$ & $\begin{array}{c}\text { Não mora no } \\
\text { domicílio }\end{array}$ & $\begin{array}{c}\text { Mora no } \\
\text { domicílio }\end{array}$ & $\begin{array}{c}\text { Não mora no } \\
\text { domicílio }\end{array}$ \\
\hline 10 a 15 anos & - & 2,1 & 2,5 & 2,8 & 1,7 & 2,5 \\
16 a 17 anos & 0,6 & 2,1 & 4,3 & 2,8 & 3,2 & 2,5 \\
\hline
\end{tabular}




\begin{tabular}{l|cc|cc|cc}
\hline 18 a 24 anos & 14,0 & 8,5 & 30,8 & 12,0 & 25,9 & 10,7 \\
25 a 29 anos & 14,3 & 10,5 & 13,2 & 11,5 & 13,6 & 11,1 \\
30 a 44 anos & 37,6 & 42,8 & 29,2 & 42,7 & 31,5 & 42,8 \\
$\begin{array}{l}45 \text { a } 59 \text { anos } \\
60 \text { anos ou } \\
\text { mais }\end{array}$ & 23,5 & 29,6 & 17,4 & 24,9 & 19,3 & 26,7 \\
\hline
\end{tabular}

Fonte: PNAD/IBGE, 2009.

Para Neto e Nazareth (2012), o fato é que há um grande número de mulheres migrantes precisando e querendo ser incorporadas ao mercado de trabalho, mas sem qualificação adequada. Daí explicar-se por que serviços de doméstica, diarista, faxineira ou babá, que não exigem qualificação e culturalmente são associados a mulheres, acabam sendo ocupações remuneradas com grande procura entre as migrantes, representando para elas, muitas vezes, a única forma de articulação com o mercado de trabalho, mesmo que irregular e informal, sem as garantias previstas em lei.

Em relação às trabalhadoras domésticas que prestam serviço em mais de um domicílio", ou conhecidas como "mensalistas" e "diaristas", observa-se, pelos dados de 1999, que 19,4\% das mulheres brancas prestavam serviço em mais de um domicílio, enquanto as mulheres negras representavam 15,5\% (Gráfico 6). Ao longo da década, esse índice aumentou: entre as brancas, para 32,1\%; entre as mulheres negras, para $27,6 \%$.

Esta reconfiguração do mercado de trabalho doméstico brasileiro aponta para novas estratégias e camuflagens em que se insere para garantir sua vitalidade. O novo formato muda as relações trabalhistas, com vantagens e desvantagens. Se, por um lado, a profissionalização do emprego doméstico oferece às candidatas a possibilidade de ir até o empregador, diminuindo os vínculos de exploração e as relações de dependência afetiva e financeira, por outro, reduz-se a possibilidade de que sejam formalizadas e amparadas pela lei e protegidas contra os riscos da capacidade laboral durante a vida.

\footnotetext{
${ }^{1}$ O questionário da Pnad não levanta a informação sobre o arranjo de trabalho da trabalhadora doméstica nem questiona se é mensalista ou diarista, mas somente se trabalha em 1 domicílio ou em mais de 1 domicílio.
} 
GRÁFICO 6 - Proporção de trabalhadoras domésticas que prestam serviço em mais de um domicílio, segundo raça/cor

Brancas Negras

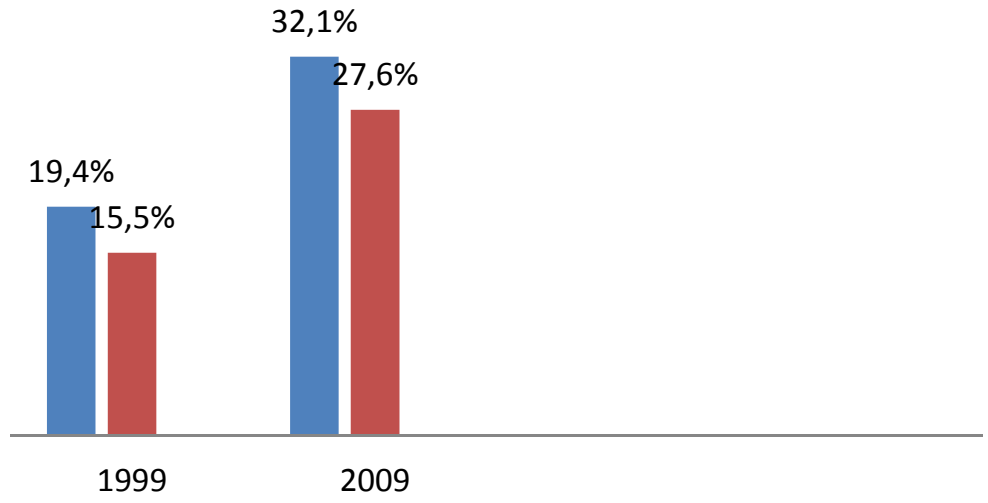

Fonte: Elaborado pelos autores com base na Pnad/IBGE, 2009.

Melo (1998) aponta que para as externas/diaristas é possível separar mais facilmente a jornada de trabalho e definir melhor a relação entre patroa e empregada.

Com a adoção da PEC 66/2012, aprovada pela Câmara dos Deputados em abril de 2013, muitos empregadores têm optado pela prestação de serviço das “diaristas”, o que não garante legalidade, pois o requisito para que se estabeleça vínculo empregatício é que haja três dias de trabalho contínuo no local da residência.

\section{Considerações Finais}

Este artigo procurou evidenciar que as mulheres negras se inserem no trabalho doméstico, mesmo tido como profissão de pouco prestígio, desvalorizado, subalternizado e nivelando a trabalhadora doméstica para baixo. É inegável que, apesar do esforço em suprimi-lo, ainda persiste o ranço sobre esta atividade, herança das velhas expressões de desigualdade experimentadas há anos por distinção de raça/cor. 
Deste modo, o trabalho doméstico é uma atividade que há muito absorve a mão de obra feminina, majoritariamente composto por negras. Observou-se um aumento da ocupação em função da autodeclaração, em maior proporção para as negras, que têm a participação e a entrada no mercado de trabalho bastante condicionada.

Houve um aumento na escolaridade das trabalhadoras domésticas negras, mas ainda não conseguiram se equiparar às brancas, até por conta dessa inferioridade escolar.

A proteção legal, positiva, por lado, aumentou, por outro, a formalização. No aspecto proteção social via contribuição à previdência, condição para reconhecimento da profissão e até mesmo de valorização, as negras estão atrás das brancas. A PEC 66/12 (PEC das Domésticas) entrou em vigência em abril de 2013: há que se esperar as novas adequações pelas quais essa atividade, agora regulamentada por lei e garantia de direitos trabalhistas, crie também um novo cenário para o trabalho doméstico. Embora se temam estratégias para se burlar a lei, confia-se que uma nova geração passe a enxergar o trabalho doméstico como uma atividade igual a outra qualquer.

Registra-se um aumento no envelhecimento da categoria. Uma das evidências pode ser o fato de o trabalho doméstico infanto-juvenil ter diminuído, devido às campanhas de conscientização, aos programas de transferências de renda e ao maior acesso à educação.

No entanto, em relação às negras, há um maior percentual de jovens que residem no local de trabalho, fato que pode ser explicado pela migração de comunidades rurais em busca de trabalho em casas de família na cidade, em troca de casa, comida e uma ajuda, além da promessa de poder estudar.

Também se observa um aumento das mulheres brancas que prestam serviço em mais de um domicílio, as chamadas “diaristas”, como reação do empregador ao advento das garantias do trabalhador doméstico. Não há como não considerar o fato um agravante para a classe, já que não há vinculo empregatício e, portanto, não há proteção social.

Assim, uma das contribuições mais importantes de estudos com foco na raça/cor e análises distintas para os dois grupos é perceber os obstáculos e as discrepâncias que permeiam o universo laboral, as dificuldades de ascensão social dos negros, e formular 
“A condição para quem nasce negra e mulher é ser doméstica?": desigualdade entre mulheres brancas e

possibilidades de superação, garantir oportunidades de vida para que a mobilidade social seja estendida a todos os estratos de nossa sociedade.

Assim, o problema do trabalho doméstico no Brasil permanece sob a roupagem de problema de classe, de gênero e de raça, aspectos até hoje associados e indissociáveis.

Algumas questões podem ser resolvidas pela luta e pelo reconhecimento das agências de luta política na mudança da legislação, para que a questão deixe de ser apenas uma simplificação do reconhecimento da categoria profissional, mas se transforme em fechamento de um ciclo histórico de desigualdade estruturante e de discriminação sistêmica. 


\section{Referências}

BENTO, Maria Aparecida Silva. A mulher negra no mercado de trabalho. Estudos Feministas, n. 2, ano 3, p. 479-488,1995.

BERNARDINO-COSTA, Joaze; FIGUEIREDO, Angela; CRUZ, Tânia. A realidade do trabalho doméstico na atualidade. 1. ed.Brasília: CFEMEA - Centro Feminista de Estudo e Assessoria., 2011.

BRITES, Jurema. Afeto, desigualdade e rebeldia: bastidores do serviço doméstico. 2000. 00 f. Tese (Doutorado em Antropologia) - Universidade Federal do Rio Grande do Sul, Porto Alegre, 2000.

CRUZ, Jamile Campos. O trabalho doméstico ontem e hoje no Brasil: legislação, políticas públicas e desigualdade. Local: UFES, Data. Disponível em:

<www.periodicos.ufes.br/SNPCCS/article/download/1632/1228>.Acesso em: 4 jul. 2011.

D’ÁVILA NETO, Maria Inácia; NAZARETH, Juliana. Redes sociais na experiência migratória de mulheres nordestinas. Disponível em:

<http:/hwww.abrapso.org.br/siteprincipal/images/Anais_XVENABRAPSO/315.\%20redes\%20sociais\%20na\%20exp eri\%CAncia\%20migrat\%D3ria\%2ode\%2omulheres\%2onordestinas.pdf). Acesso em: 23 out. 2012.

DEPARTAMENTO INTERSINDICAL DE ESTATÍSTICA E ESTUDOS SOCIOECONÔMICO. A mulher negra no mercado de trabalho metropolitano: inserção marcada pela dupla discriminação. Estudos e Pesquisas, ano II, n. 14, 2005. Disponível em <http://portal.mte.gov.br/data/files/FF8080812CB90335012CC6DC77186908/estpesq141120 05_mulhernegra.pdf >.

FREITAS, Jefferson Belarmino. Estigma racial e emprego doméstico. In: RODRIGUES, V. J. (Ed.). Retratos e espelhos: raça e etnicidade no Brasil e nos Estados Unidos. São Paulo: FEA/USP, 2009.

HASENBALG, Carlos. Discriminação e desigualdade raciais no Brasil. Rio de Janeiro: Editora Graal, 1979.

HIRATA, Helena. Trabalho doméstico: uma servidão voluntária? In: GODINHO, T.;

SILVEIRA, M. L. Coleção cadernos da Coordenadoria Especial da Mulher - PMSP - Políticas públicas e igualdade de gênero, n. 8, dez. p. 43-54, 2004. 
HOOKS, Bell. Intelectuais negras. Estudos Feministas, Rio de Janeiro: IFCS/UERJ e PPCIS/UERJ, v. 3, n. 2, p. 464-479. 1995.

INSTITUTO DE PESQUISA ECONÔMICA APLICADA. Situação das trabalhadoras doméstica no país. Comunicado IPEA, n. 90, maio. 2011,

MATTOS, Miguel Ragone. Trabalhadores urbanos e domésticos: a constituição federal e sua assimetria. Estudos Feministas, n. 17, v. 3, p. 871-878, set./dez. 2009.

MELO, Hildette Pereira. O serviço doméstico remunerado no Brasil: de criadas a trabalhadoras. Rio de Janeiro: IPEA, 1998.

MELO, Hildette Pereira.; DI SABBATO, Alberto. Trabalhadoras domésticas: eterna ocupação feminina. Até quando? In: BARSTED, L. L.; PITANGUY, J. (Orgs.). O progresso das mulheres no Brasil, 2003-2010. Rio de Janeiro: CEPIA, Brasília: ONU Mulheres, 2011.

MONTAGNER, Paula. A reestruturação produtiva e o desemprego da mulher. In: COSTA, Ana Alice et al (Org.). Reconfiguração das relações de gênero no trabalho. São Paulo: CUT BRASIL, 2004.

ORGANIZAÇÃO INTERNACIONAL DO TRABALHO. Trabalho digno para o trabalho doméstico. Portugal: Edigraf, 2010. Conferência Internacional do Trabalho, 99. ' Sessão. Relatório IV(1). Disponível em:< http:/hwww.ilo.org/public/portugue/region/eurpro/lisbon/pdf/pub_trabdomestico.pdf>. Acesso em: 4 de dez. 2012.

PARKIN, Frankin. Estratificação social. In: BOTTOMORE, T.; NISBET, R. (Orgs.). História da Análise Sociológica. Zahar Editores, Rio de Janeiro, 1980.

PINHEIRO, L. et al. Retrato das desigualdades, 2. ed., UNIFEM/IPEA, 2006.

SANCHES, S. Trabalho doméstico: desafios para o trabalho decente. Estudos Feministas, Florianópolis, v. 17, n. 3, p. 879-888, set./dez. 2009.

SILVA Ferreira, Denise; LIMA, Márcia. Raça, gênero e mercado de trabalho. Estudos Afroasiáticos. Rio de Janeiro, n. 23, p.00-00, dez. 1992.

SOUZA, Andréa Alcione. A trajetória de gestores negros no mercado de trabalho da região metropolitana de Belo Horizonte. In: XI CONGRESSO LUSO AFRO BRASILEIRO DE CIÊNCIAS SOCIAIS, Salvador, 7 a 10 ago. 2011. Anais... Salvador: Editor, 2011.

TUMIN, Melvin. Estratificação social. São Paulo: Pioneira, 1970. 
“A condição para quem nasce negra e mulher é ser doméstica?”: desigualdade entre mulheres brancas e negras no trabalho doméstico

Guélmer Júnior Almeida de Faria - Maria da Luz Alves Ferreira - Caroline Marci Fagundes Coutinho

Recebido em: 18/09/2013 Aprovado em: 28/11/2013

Universidade do Estado de Santa Catarina - UDESC Centro de Ciências Humanas e da Educação - FAED

Revista PerCursos

Volume 15 - Número 28 - Ano 2014 revistapercursos@gmail.com 